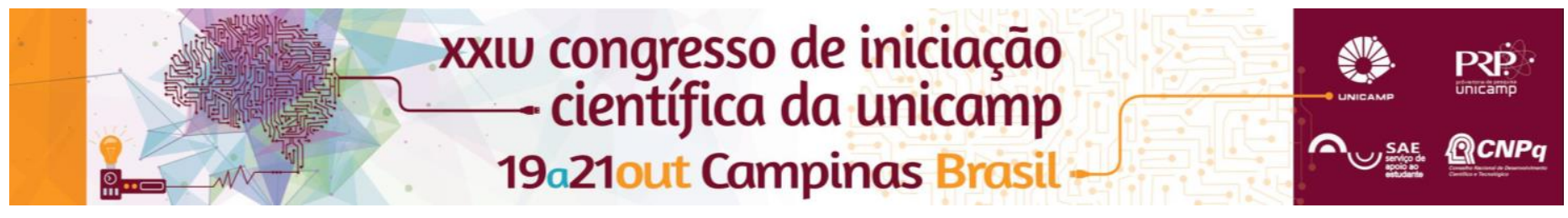

\title{
Substituição do PGPR por lecitina de soja em emulsão A/O tipo HIPE: efeito do processo
}

\author{
Matheus A. Adame*, Paula K. Okuro, Andresa Gomes, Ana L. Rodrigues, Rosiane L. da Cunha
}

\begin{abstract}
Resumo
A estabilidade cinética de emulsões pode ser alcançada através da utilização de surfactantes. Este trabalho teve como objetivo avaliar a viabilidade da substituição total ou parcial do poliglicerol poliricinoleato (PGPR), um surfactante semisintético, por um surfactante natural, lecitina de soja. Foram realizadas análises reológicas, distribuição de tamanho e tamanho médio de gotas, estabilidade e microscopia.
\end{abstract}

\section{Palavras-chave:}

Lecitina de soja, mistura de surfactantes, emulsão

\section{Introdução}

Emulsões são sistemas constituídos de dois líquidos imiscíveis, onde gotas de uma fase dispersa estão envoltas por uma fase contínua. Se a fase dispersa for água e a fase contínua óleo, caracteriza-se a emulsão do tipo água/óleo $(\mathrm{A} / \mathrm{O})$, caso contrário óleo/água $(\mathrm{O} / \mathrm{A})$. Trata-se de sistemas termodinamicamente instáveis, onde é necessária a adição de um emulsificante para sua estabilização (Tadros, 2009). Emulsões A/O possuem diversas aplicações nos segmentos alimentícios e, em geral, são estabilizadas principalmente devido à formação de cristais de gordura que impedem a mobilidade molecular devido ao aumento da viscosidade da fase contínua. Em contrapartida, emulsões líquidas $\mathrm{A} / \mathrm{O}$ são muito instáveis devido à baixa viscosidade, sendo as emulsões HIPE (High Internal Phase Emulsion), uma alternativa, devido à grande quantidade de fase dispersa, para superar este problema tecnológico (Ushikubo; Cunha, 2014). PGPR e lecitina são emulsificantes utilizados na estabilização de emulsões $\mathrm{A} / \mathrm{O}$, sendo a lecitina um fosfolipídio de origem natural, e reconhecido como seguro ("generally recognized as safe" - GRAS) segundo o FDA. Nesse contexto, este trabalho buscou uma substituição parcial do PGPR, um emulsificante semissintético de uso regulado em alimentos, pela lecitina, em emulsões HIPE.

\section{Resultados e Discussão}

Inicialmente foram testadas diferentes proporções de emulsificante, razões das fases e densidades energéticas no preparo das emulsões. A partir dos resultados, foi definida a razão mássica da fase $A / O$ 75:25. Foram estudadas formulações com $0 \%, 0,5 \%$, $1,0 \%, 1,5 \%$ de lecitina, onde a quantidade de PGPR complementava a de lecitina para a soma de $2 \%(\mathrm{~m} / \mathrm{m})$ total no sistema. As emulsões apresentaram diâmetro

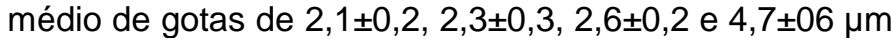
para o aumento de lecitina respectivamente. Observouse que a formulação com 1,5 \% de lecitina apresentou maiores diâmetros médios de gotas, enquanto que as demais não apresentaram diferença significativa entre si. O comportamento foi confirmado na análise de microscopia óptica. Todas as emulsões apresentaram comportamento pseudoplástico devido à alta fração de fase dispersa que causou maior interação gota-gota, porém essas interações são fracas e quebradas com o aumento da taxa de cisalhamento. Além disso, observouse que as emulsões com maior quantidade de PGPR apresentou maior viscosidade, o que pode ser justificado pelo menor tamanho de gota e, portanto, maior interação hidrodinâmica entre as gotas de água.

Tal comportamento ainda pode estar associado com a formação de estruturas estáveis, como micelas reversas na fase contínua o que dificultaria o alinhamento das gotas na direção do campo de cisalhamento, causando uma resistência ao escoamento, e consequentemente aumento de viscosidade. Contudo, a viscosidade da emulsão com 1,5\% de lecitina e 0,5 \% de PGPR foi superior a das formulações com 1 e $0,5 \%$ de lecitina. Este resultado não esperado pode estar associado ao início de uma separação de fases. Além disso, com o objetivo de reduzir o tamanho das gotas, as emulsões foram submetidas a homogeneização à alta pressão (20/5 MPa). Todas as emulsões apresentaram comportamento de fluido newtoniano, com significativa redução na viscosidade. Após este tratamento, as emulsões mostraram redução do tamanho médio de gotas, com o aumento da concentração de lecitina. Este resultado difere do observado para as emulsões primárias (não submetidas ao processo de alta pressão), indicando que pode ter ocorrido inversão de fases, devido às altas cargas energéticas aplicadas, gerando emulsões do tipo O/A.

\section{Conclusões}

As emulsões primárias apresentaram diminuição da viscosidade com o aumento da concentração de lecitina até $1 \%$. Porém não foi observado aumento no tamanho médio de gotas, indicando que o PGPR pode ser substituído parcialmente pela lecitina. Portanto, as emulsões HIPE produzidas neste estudo são sistemas com potencial utilização em produtos alimentícios que requerem diferentes características reológicas. As emulsões após serem submetidas à alta pressão apresentaram redução da viscosidade e aumento do diâmetro médio das gotas com a diminuição do PGPR, com possível inversão de fases, indicando que 0 processo de alta pressão não é apropriado para produção de emulsões $\mathrm{A} / \mathrm{O} \mathrm{com}$ alta fração de fase dispersa.

\section{Agradecimentos}

Ao $\mathrm{CNPq}$ pelo apoio à pesquisa.

TADROS, T.F. Emulsion Science and Technology. Weinheim: WILEY-VCH, p.326, 2009.

USHIKUBO, F.Y.; CUNHA, R.L. Stability mechanisms of liquid water-in-oil emulsions. Food Hydrocolloids, v.34, p.145-153, 2014. 